\title{
Effect of Trans-Polyoctylene Rubber on the Polypropylene/Recycled Acrylonitrile Butadiene Rubber/Empty Fruit Bunch Composites
}

\author{
Nurul Syazwani Othman* and Ragunathan Santiagoo \\ School of Environmental Engineering, Universiti Malaysia Perlis, \\ Kompleks Pengajian Jejawi 3, 02600 Arau, Perlis, Malaysia \\ "Corresponding author: wanienurul91@yahoo.com
}

Published online: 30 June 2020

To cite this article: Nurul Syazwani Othman and Ragunathan Santiagoo (2020). Effect of trans-polyoctylene rubber on the polypropylene/recycled acrylonitrile butadiene rubber/empty fruit bunch composites. Journal of Engineering Science, 16(1), 19-28, https://doi.org/10.21315/jes2020.16.1.2.

To link to this article: https://doi.org/10.21315/jes2020.16.1.2

\begin{abstract}
The fabrication of new thermoplastic elastomer (TPE) composites made up from polyproylene (PP), recycled acrylonitrile butadiene rubber (NBRr) and empty fruit bunch fibre (EFB) were investigated. The composites with and without trans-polyoctylene rubber (TOR) as compatibiliser was also studied. PP/NBRr/EFB composite samples were prepared by using a heated two-roll mill at $180^{\circ} \mathrm{C}$ for $11 \mathrm{~min}$. The composites were moulded by using hot press machines at temperature $180^{\circ} \mathrm{C}$ within $11 \mathrm{~min}$. The ratio of composite investigated were 100/0/10, 80/20/10, 70/30/10, 60/40/10, 50/50/10 and 40/60/10. Meanwhile, the ratio of TOR was fixed at $10 \mathrm{phr}$ for composite with compatibiliser. The tensile strength, Young's modulus and elongation at break $\left(E_{b}\right)$ were recorded using INSTRON Universal Testing machine. The morphological properties of composites were performed using scanning electron microscope (SEM). The chemical structure of PP/NBRr/EFB composites was also analysed using Fourier-transform infrared (FTIR) spectrum. It was found that the tensile strength and Young's modulus were decreased with increasing of NBRr loading while the $E_{b}$ was increased. The morphological examination indicated that the presence of TOR compatibilisers showed improvement in adhesion and better interfacial bonding between filler and matrix. This can be seen clearly under morphological and spectral studies of PP/NBRr/EFB and PP/NBRr/EFB/TOR composites.
\end{abstract}

Keywords: trans-polyoctylene rubber, polypropylene, recycled acrylonitrile butadiene rubber, empty fruit bunch fibre, thermoplastic elastomer composites 


\section{INTRODUCTION}

Due to the environmental concerns, the product development from recycled materials is a must in order to maximise the benefits. Remanufacture of product leads to a number of economic opportunities as it being used in many areas such as in energy sources, civil engineering and polymer composites. The fabrication of polymer composites by using waste rubber materials is highlighted in this paper as it is also known as thermoplastic elastomer (TPE). TPE composites are extensively used in many applications such as door or window handle for household, plastic furniture, railings and others. TPE composite generally is the combination of plastic and rubber materials which give elastic effect and easy to process. Low in cost, excellent mechanical strength, light weight, corrosion resistance and able to be tailored for particular engineering utility are some of the criteria of TPE composites that might not observed in any other materials. ${ }^{1}$ Previous study was done by many researchers on recycling rubber waste materials to ensure the sustainable management of waste products. ${ }^{2-4}$ The composite with waste rubber fillers has created a new sustainable material and has potential to be applied into various fields.

Rejected rubber gloves is one type of rubber waste materials which contribute to the amount of waste rubber generated worldwide. Rubber gloves were usually discarded and dumped as garbage and become threat to the environment. Not only that, higher number of glove disposal also contributed by the high reject rate during the production process due to strict product specifications. The high number of waste rubber gloves have related to the demand of rubber glove products since the rises of healthcare awareness issue. In Malaysia, there is $26 \%$ increment of rubber gloves export for the first quarter of 2017 compare to 2016. High usage of rubber gloves has led to high disposal of used gloves. Several literatures have reported that composites with waste rubber gloves fillers shows better mechanical properties such as better impact strength and lower stiffness.

To be updated, the addition of natural fibre in polymer materials becomes part of the researcher attentiveness to manufacture diverse environmental friendly composites materials. Examples of natural fibre or filler used are hemp, flax, wood, cotton, peanut shell powder, ${ }^{5}$ kenaf, empty fruit bunch and many others. ${ }^{6,7}$ Empty fruit bunch (EFB) has growing interest to be used as composite reinforcement due to good mechanical properties. Not only that, the addition of natural fibre is purposely to reduce the use of petroleum sources and make it more biodegradable polymer plastic-based materials. However, the main constraint is the incompatibility between natural fibre and polymer plastic material. 
Weak of interfacial adhesion between the matrix and filler was resulted due to hydrophilic nature of fibre and hydrophobic of polymer matrix. Trans-polyoctylene rubber (TOR) is a low-molecular-weight polymer made from cyclo-octene with the aid of metathesis polymerisation and has been recognised as a compatibiliser for incompatible blends as well as a processing aid. ${ }^{8}$ Therefore, addition of TOR is required in order to improve the interfacial adhesion of composites and produce better composite performance. The aim of this research is to study the mechanical and morphological properties of polyproylene (PP)/recycled acrylonitrile butadiene rubber (NBRr)/EFB composite with and without TOR compatibiliser.

\section{METHODOLOGY}

\subsection{Material Preparation}

PP was supplied from Titan PP Polymers Sdn. Bhd. (code 6331) with density $0.9 \mathrm{~g} \mathrm{~cm}^{-3}$. The NBRr was obtained from Juara One Resources (M) Sdn. Bhd. The gloves were cut and masticated several times to obtain small particle size using a pulverise machine model RT-34 from Rong Tsong Precision Technology Co. EFB was collected at United Oil Palm Industries Sdn. Bhd. Firstly, oil palm EFB fibre was dried in the oven with temperature $90^{\circ} \mathrm{C}$ for $24 \mathrm{~h}$ to remove moisture content. Then, oil palm EFB fibre was grinded and sieved into powder form with particle size less than $300 \mu \mathrm{m}$. It was dried again to remove excessive moisture. The TOR was supplied from Sigma-Aldrich (M) Sdn. Bhd.

\subsection{Mixing and Compounding}

PP, NBRr, EFB and TOR were weighted according to the formulation given in Table 1. All the material except TOR were dried in an oven at $80^{\circ} \mathrm{C}$ for $24 \mathrm{~h}$ before mixing. PP, NBRr and EFB were mixed together by using a heated two roll mill at temperature $180^{\circ} \mathrm{C}$ for $11 \mathrm{~min}$. The mixing sequence for $\mathrm{PP} / \mathrm{NBRr} / \mathrm{EFB}$ with and without TOR is showed in Table 2. For formulation series, PP was melted for 4 min follow by the addition of NBRr. The addition of EFB were added at minutes of sixth and kept mixing for another $3 \mathrm{~min}$ and the composite were discharged when the total mixing were $11 \mathrm{~min}$. For the composites with TOR compatibiliser, it was added into the mixture at the 9 th min. 
Table 1: Formulation of PP/NBRr/EFB and PP/NBRr/EFB composites

\begin{tabular}{lcccccccccccc}
\hline \multirow{2}{*}{ Material } & \multicolumn{4}{c}{ PP/NBRr/EFB composites (phr) } & \multicolumn{4}{c}{ PP/NBRr/EFB/TOR composites (phr) } \\
\cline { 2 - 12 } & S1 & S2 & S3 & S4 & S5 & S6 & S7 & S8 & S9 & S10 & S11 & S12 \\
\hline PP & 100 & 80 & 70 & 60 & 50 & 40 & 100 & 80 & 70 & 60 & 50 & 40 \\
NBRr & 0 & 20 & 30 & 40 & 50 & 60 & 0 & 20 & 30 & 40 & 50 & 60 \\
EFB & 10 & 10 & 10 & 10 & 10 & 10 & 10 & 10 & 10 & 10 & 10 & 10 \\
TOR & - & - & - & - & - & - & 10 & 10 & 10 & 10 & 10 & 10 \\
\hline
\end{tabular}

Table 2: The mixing sequence of the composites

\begin{tabular}{ccc}
\hline \multirow{2}{*}{ Time (min) added to the heated two-roll mill } & \multicolumn{2}{c}{ Mixture sequences of composite } \\
\cline { 2 - 3 } & PP/NBRr/EFB & PP/NBRr/EFB/TOR \\
\hline 0 & $\mathrm{PP}$ & $\mathrm{PP}$ \\
4 & $\mathrm{NBRr}$ & $\mathrm{NBRr}$ \\
6 & $\mathrm{EFB}$ & $\mathrm{EFB}$ \\
9 & - & TOR \\
11 & Discharge & Discharge \\
\hline
\end{tabular}

\subsection{Sample Preparation}

After mixing process, the compounds were ready to compress into $1 \mathrm{~mm}$ thin sheet using the electrical heated hydraulic press model GT-7014-A300C with $15 \mathrm{Kpa}$ of pressure at $180^{\circ} \mathrm{C}$ within $11 \mathrm{~min}$. Preheating was allowed for $7 \mathrm{~min}, 2 \mathrm{~min}$ for compression and another $2 \mathrm{~min}$ for cooling pressed. Then, all the $1 \mathrm{~mm}$ thin sheets samples were cut into dumb bell shape by using a Wallace die cutter model S6/1/6.A.

\subsection{Testing and Characterisation Analysis}

Tensile testing was conducted using universal testing machine (UTM) model Instron 3366. This tensile test were operated accordance to ASTM D 638 Standard Test Method to get the tensile strength, Young's modulus and elongation at break $\left(E_{b}\right)$ with cross head speed of $5 \mathrm{~mm} \mathrm{~min}^{-1}$. Studies of morphological surfaces of PP/NBRr/EFB with and without TOR were carried out using a scanning electron microscope (SEM) machine. The selected fractures specimens were coated with a thin layer of platinium using auto fine coater JFC1600 to prevent electrostatic charging and to avoid a poor image resolution during the process. Analysis of Fourier-transform infrared (FTIR) of the composites was analysed using a Perkin-Elmer System 2000 analyser. The scanning range that was used between 4000 to $500 \mathrm{~cm}^{-1}$. 


\section{RESULT AND DISCUSSION}

\subsection{Tensile Testing}

The graph of tensile strength and Young's modulus of PP/NBRr/EFB composites and PP/NBRr/EFB/TOR composites is shown in Figures 1 and 2. From the result obtained, the tensile strength and Young's modulus of composites were decreased with increasing of NBRr loading. This might due to the low interaction between the PP and NBRr matrices. The weak structure produced in the composite might due to the formation of interphase discontinuity between filler and matrices. ${ }^{9}$ However, $\mathrm{PP} / \mathrm{NBRr} / \mathrm{EFB} / \mathrm{TOR}$ composite show higher tensile strength and Young's modulus compared to $\mathrm{PP} / \mathrm{NBRr} / \mathrm{EFB}$ composite. This is due to the present of TOR as compatibiliser which act as processing aid that enhanced the adhesion of PP and NBRr matrices. Besides, the characteristic of TOR which inherits low viscosity was possible to locate at the interfacial area between the matrices. ${ }^{10}$

The $E_{b}$ of PP/NBRr/EFB composite with and without TOR compatibiliser is shown in Figure 3. It was observed that, the $E_{b}$ was increased while increasing the NBRr loading in both composites. This result might be caused the stiffness of the composite decreased with increasing content of elastomer. Besides, the graph shows the composite with the presence of compatibiliser which is TOR higher than the composite without compatibiliser even at similar filler loading. This trend occurs might due to the strong interaction of EFB filler with PP/NBRr matrix in the presence of TOR compatibiliser. ${ }^{11}$

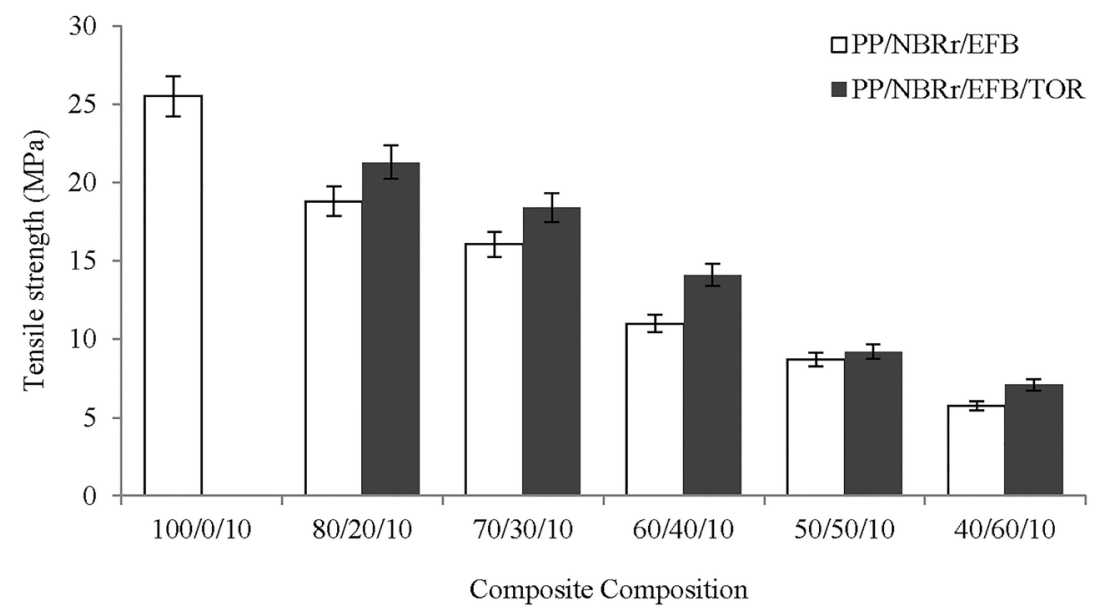

Figure 1: $\mathrm{PP} / \mathrm{NBRr} / \mathrm{EFB}$ and $\mathrm{PP} / \mathrm{NBRr} / \mathrm{EFB} / \mathrm{TOR}$ composites of tensile strength. 


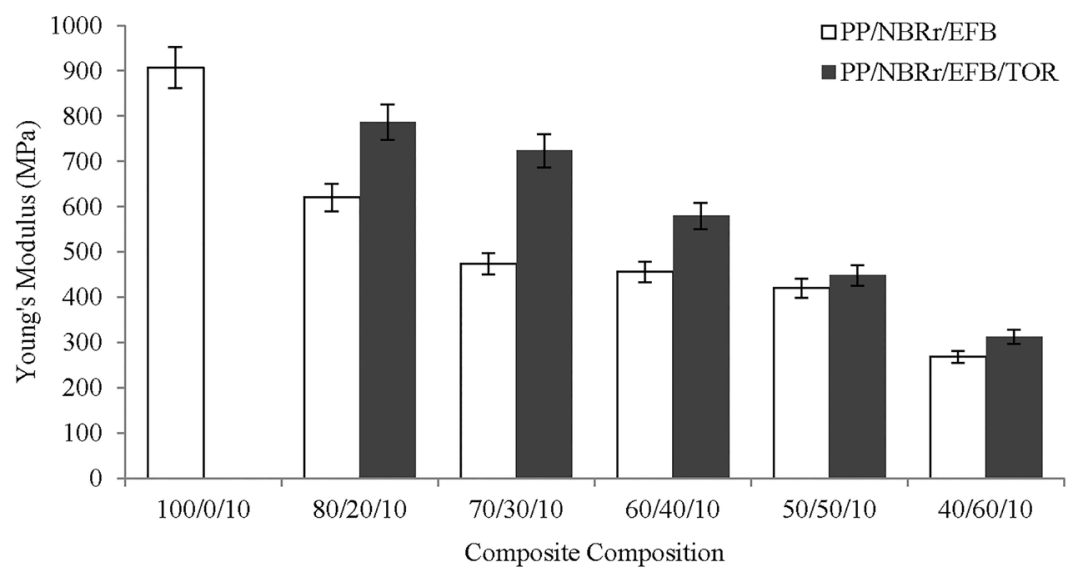

Figure 2: The Young's modulus for PP/NBRr/EFB composite with and without TOR.

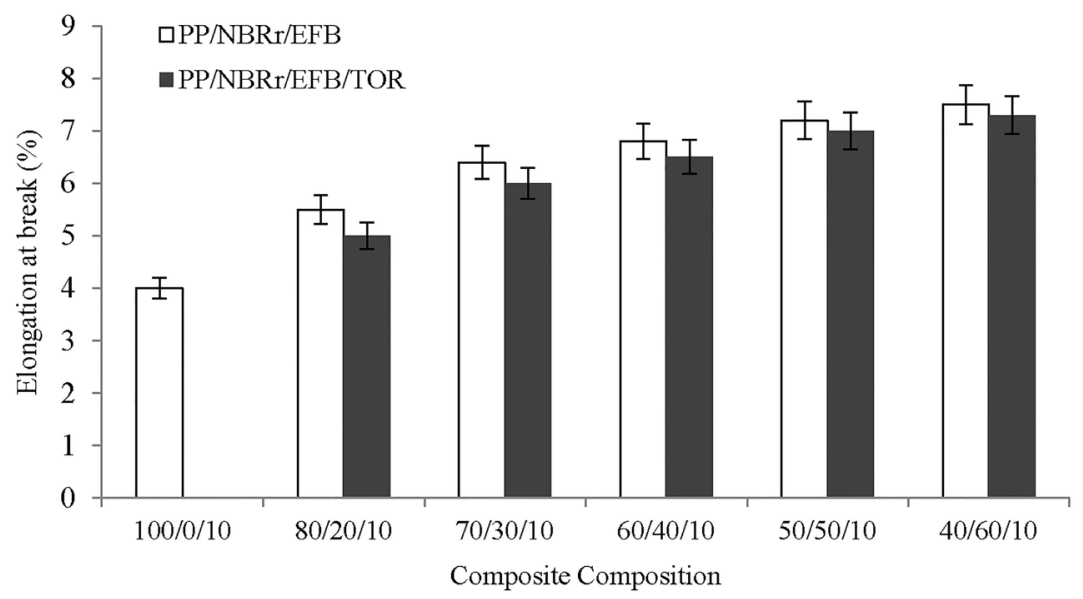

Figure 3: The $E_{b}$ of PP/NBRr/EFB composite with and without TOR.

\subsection{Morphological Properties}

Figures 4(a) and 4(b) show SEM micrograph of fracture surface of PP/NBRr/EFB composites at compositions 70/30/10 and 60/40/10, respectively. There are holes and uneven distributed NBRr throughout both of the composites. The holes are generally caused by the pull out or detachment of EFB filler as well as NBRr matrix. This is due to the low interaction between filler and matrix. Since EFB are hydrophilic in nature, the incorporation into the polymer blends causes the heterogeneous systems which then lead to the lack of adhesion between the filler and matrix. ${ }^{11}$ 


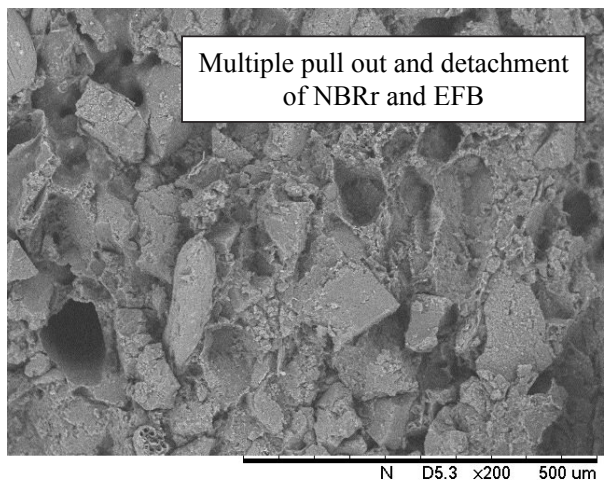

(a)

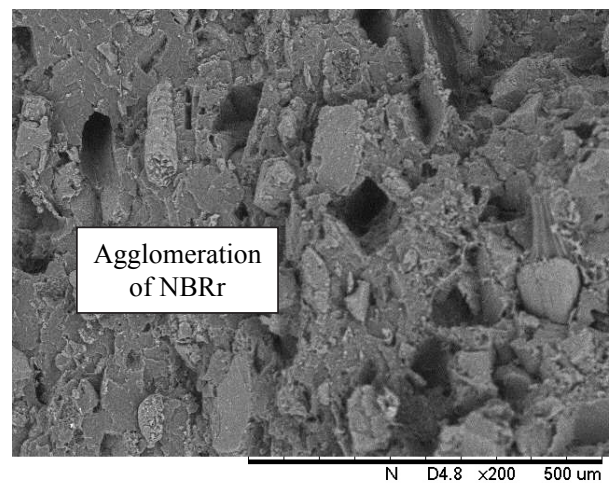

(b)

Figure 4: SEM micrograph of PP/NBRr/EFB composite with the ration of (a) 70/30/10 and (b) $40 / 60 / 10$ at magnification of $200 \times$.

Figures 5(a) and 5(b) show the SEM micrograph of fracture surface of $\mathrm{PP} / \mathrm{NBRr} / \mathrm{EFB} / \mathrm{TOR}$ at composition $70 / 30 / 10$ and 60/40/10, respectively. From both micrograph, it can be seen that, the composite were well blended since its shows less pull out of EFB filler and the EFB filler were encapsulate well in the matrix. In addition, the present of TOR as compatibiliser shows better smooth surface compare to the composite without TOR compatibiliser. The existing of TOR also tends to well encapsulate of filler into the TPE. From the observation, there is strongly support the earlier finding that, by addition of TOR, better interfacial adhesion between the EFB filler and NBRr matrices were created. It can be speculated that TOR which has lower viscosity may locate at the interface between the PP and NBRr phases. ${ }^{8}$

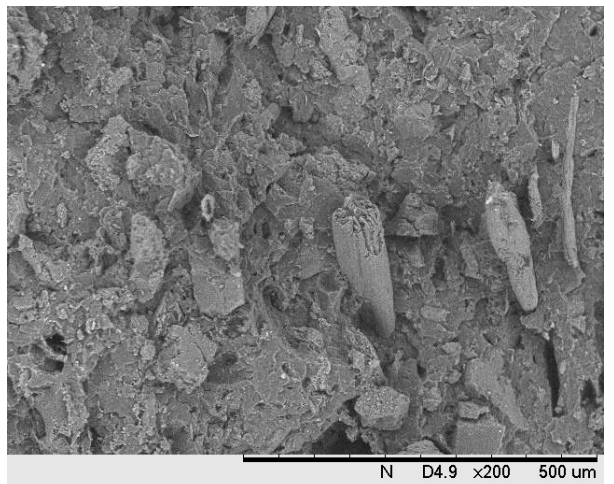

(a)

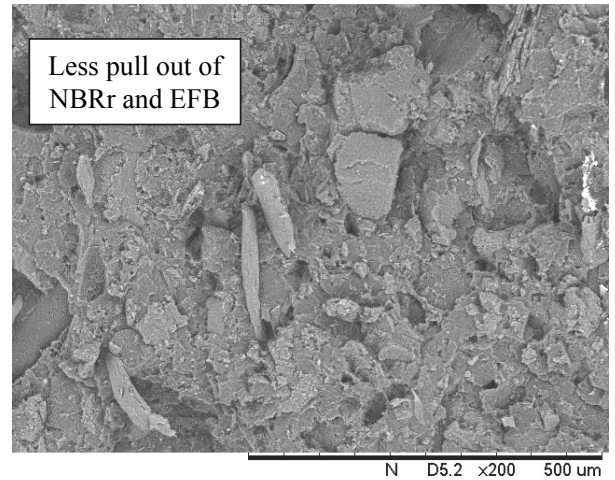

(b)

Figure 5: SEM micrograph of $\mathrm{PP} / \mathrm{NBRr} / \mathrm{EFB} / \mathrm{TOR}$ composite with the ratio of (a) $70 / 30 / 10 / 10$ and (b) $40 / 60 / 10 / 10$ at magnification of $200 \times$. 


\subsection{FTIR Analysis}

Figure 6 shows the comparison of FTIR spectra of PP/NBRr/EFB and PP/NBRr/ $\mathrm{EFB} / \mathrm{TOR}$ composites at ratio 70/30/10. The existence of characteristic peak at the $1,651 \mathrm{~cm}^{-1}$ was due to increase the intensity of $\mathrm{C}=\mathrm{C}$ stretching from the alkenes groups of TOR compatibiliser. TOR shows its absorption band at $1,257 \mathrm{~cm}^{-1}$ assign to the absorption by alkyl halides groups of $\mathrm{C}-\mathrm{H}$, as it might interact with PP matrix. This finding suggests that the addition of TOR, interaction with PP matrix has made the composites improve the interfacial adhesion between EFB filler and NBRr matrix. Figure 7 shows the proposed mechanism of $\mathrm{PP} / \mathrm{NBRr} /$ RFB/TOR composites.

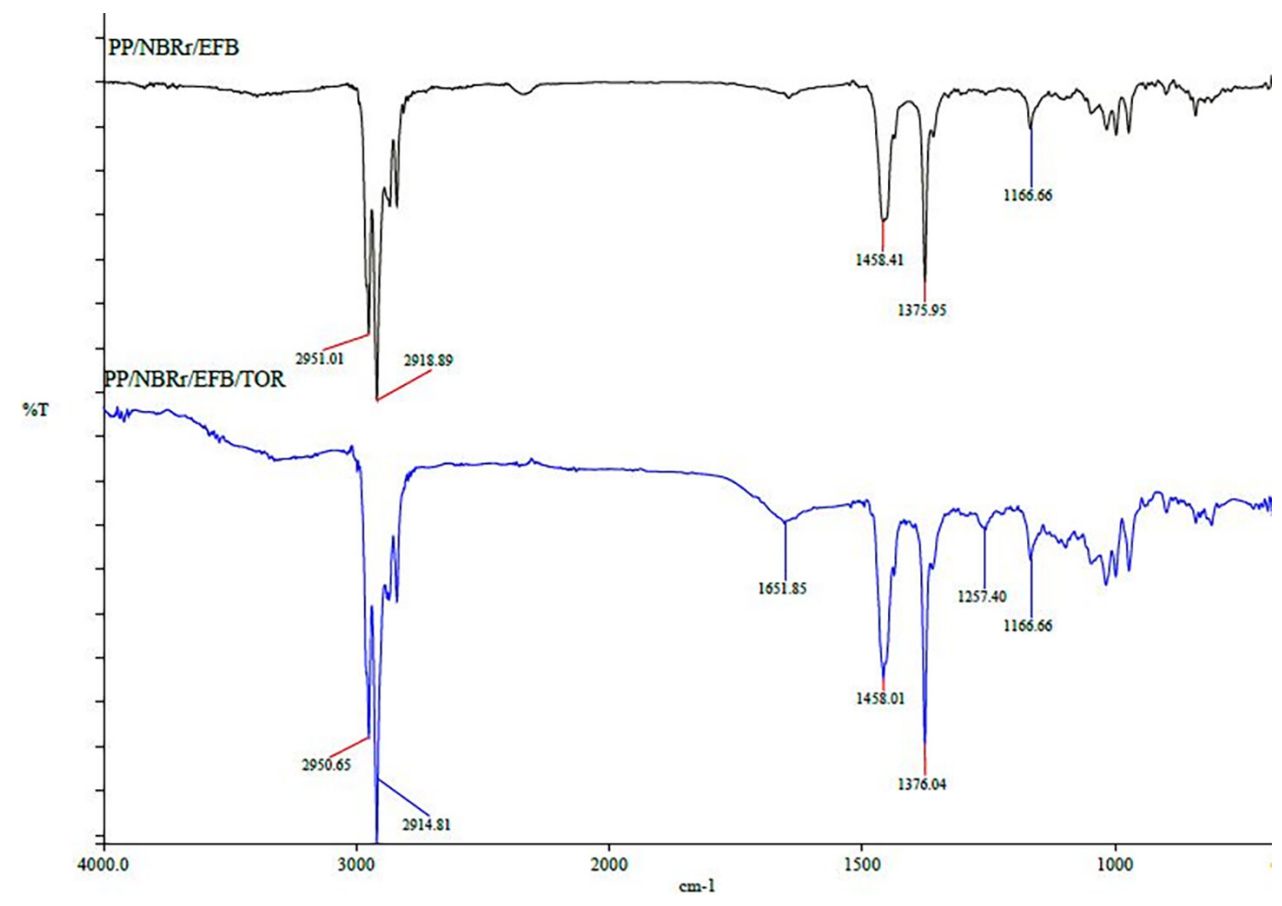

Figure 6: FTIR spectra of PP/NBRr/EFB and PP/NBRr/EFB/TOR composites. 


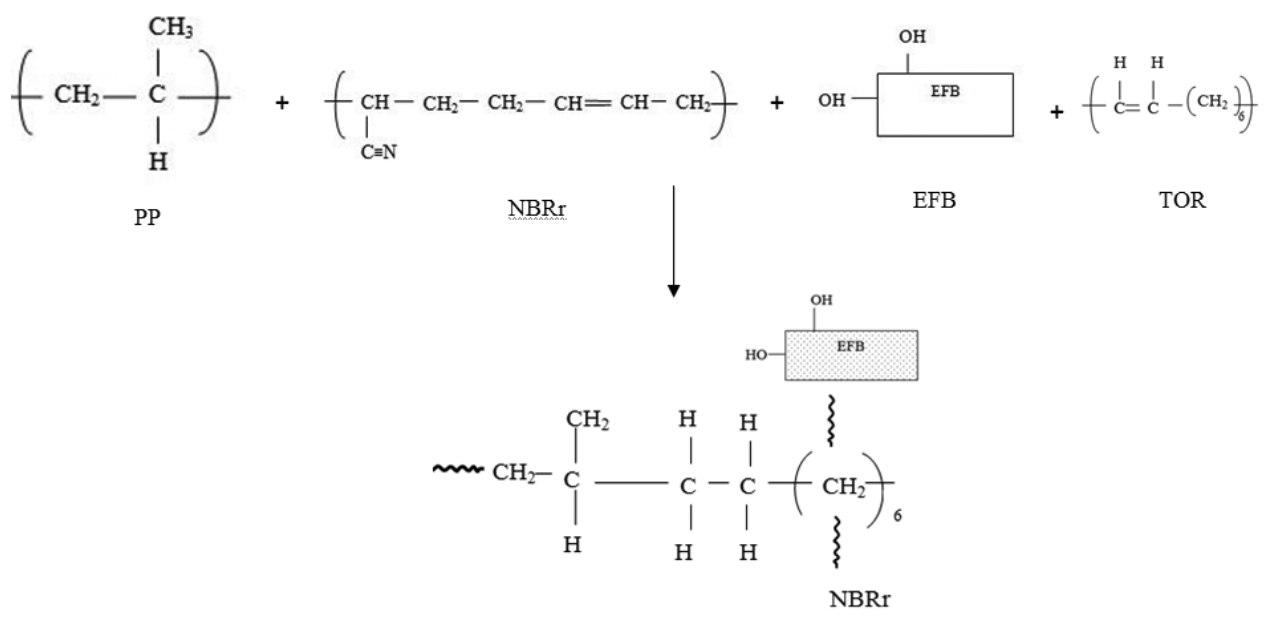

Figure 7: Proposed mechanism of PP/NBRr/EFB/TOR composites.

\section{CONCLUSION}

The tensile strength and Young's modulus with the present of TOR as compatibiliser shows that higher result compare to the composite without compatibiliser. The elongation shows lower trend compare to without TOR due to the increasing of the elastomer content in the composite. Then, from the SEM result, can be conclude that, the existing TOR in the composite would give a better interfacial adhesion. This is because the improvement in homogeneity caused the filler encapsulated in the matrix.

\section{REFERENCES}

1. Amin, S. \& Amin, M. (2011). Thermoplastic elastomeric (TPE) materials and their use in outdoor electrical insulation. Rev. Adv. Mater. Sci., 29(1), $15-30$.

2. Rashad, A. M. (2016). A comprehensive overview about recycling rubber as fine aggregate replacement in traditional cementitious materials. Int. J. Sustain. Built Environ., 5(1), 46-82, https://doi.org/10.1016/j. ijsbe.2015.11.003.

3. Yehia, A. A. (2004). Recycling of rubber waste. Polym. Plast. Technol. Eng., 43(6), 1735-1754, https://doi.org/10.1081/PPT-200040086. 
4. Nuzaimah, M. Sapuan, S. M. Nadlene, R. \& Jawaid, M. (2018). Recycling of waste rubber as fillers: A review. Conf. Ser.: Mater. Sci. Eng., 368, 012016.

5. Zaaba, N. F., Jaafar, M. \& Ismail, H. (2017). The effect of alkaline peroxide pre-treatment on properties of peanut shell powder filled recycled polypropylene composites. J. Eng. Sci., 13, 75-87.

6. Thakur, V. K., Thakur, M. K. \& Gupta, R. K. (2014). Review: Raw natural fiber-based polymer composites. Int. J. Polym. Anal. Charact., 19(3), 256-271, https://doi.org/10.1080/1023666X.2014.880016.

7. Romli, A. Z., Mustakim, M. and Ghaztar, M. (2017). The fibre damage due to the mechanical cutting of treated and untreated kenaf short fibre/ unsaturated polyester composite. J. Eng. Sci., 13, 63-74, https://doi. org/10.21315/jes2017.13.5.

8. Chang, Y. W., Shin, Y. S., Chun, H. \& Nah, C. (1999). Effects of transpolyoctylene rubber (TOR) on the properties of NR/EPDM blends. J. Appl. Polym. Sci., 73(5), 749-756, https://doi.org/10.1002/(SICI)10974628(19990801)73:5<749::AID-APP15>3.0.CO;2-S.

9. Santiagoo, R., Ting, S. S., Ismail, H. \& Jaafar, M. (2015). Tensile properties of linear low density polyethylene (LLDPE)/recycled acrylonitrile butadiene rubber (NBRr)/rice husk powder (RHP) composites. Appl. Mech. Mater., 754-755, 210-214, https://doi. org/10.4028/www.scientific.net/AMM.754-755.210.

10. Awang, M., Ismail, H. \& Hazizan, M. A. (2007). Polypropylene-based blends containing waste tire dust: Effects of trans-polyoctylene rubber (TOR) and dynamic vulcanization. Polym. Test., 26(6), 779-787, https://doi.org/10.1016/j.polymertesting.2007.04.007.

11. Saheb, D. N. \& Jog, J. P. (1999). Natural fiber polymer composites: A review. Adv. Polym. Technol., 18(4), 351-363, https://doi.org/10.1002/ (SICI)1098-2329(199924)18:4<351::AID-ADV6>3.0.CO;2-X. 